Revue Revue de l'histoire des religions

$$
\begin{array}{cc}
\text { de I'histoire } & 3 \mid 2012 \\
\text { des religions } & \text { Varia }
\end{array}
$$

Marco GUIDA, Una leggenda in cerca d'autore : la Vita di santa Chiara d'Assisi. Studio delle fonti e sinossi intertestuale

Préface de Jacques DALARUN, Bruxelles, Société des Bollandistes («Subsidia hagiographica », 90), 2010, $25 \mathrm{~cm}$, IX-255 p., $65 €$, ISBN 978-2-87365-024-7.

\title{
Cécile Lanéry
}

\section{OpenEdition}

Journals

Édition électronique

URL : http://journals.openedition.org/rhr/7942

DOI : $10.4000 /$ rhr.7942

ISSN : 2105-2573

Éditeur

Armand Colin

Édition imprimée

Date de publication : 1 septembre 2012

Pagination : 444-446

ISBN : 978-2200-92975-0

ISSN : 0035-1423

Référence électronique

Cécile Lanéry, « Marco guida, Una leggenda in cerca d'autore : la Vita di santa Chiara d'Assisi. Studio delle fonti e sinossi intertestuale », Revue de l'histoire des religions [En ligne], 3 | 2012, mis en ligne le 04 octobre 2012, consulté le 22 septembre 2020. URL : http://journals.openedition.org/rhr/7942 ; DOI https://doi.org/10.4000/rhr.7942

Ce document a été généré automatiquement le 22 septembre 2020

Tous droits réservés 


\section{Marco GUIDA, Una leggenda in cerca d'autore : la Vita di santa Chiara d'Assisi. Studio delle fonti e sinossi intertestuale}

Préface de Jacques DALARUN, Bruxelles, Société des Bollandistes ("Subsidia hagiographica », 90), 2010, $25 \mathrm{~cm}$, IX-255 p., $65 €$, ISBN 978-2-87365-024-7.

\section{Cécile Lanéry}

\section{RÉFÉRENCE}

Marco GUIDA, Una leggenda in cerca d'autore : la Vita di santa Chiara d'Assisi. Studio delle fonti e sinossi intertestuale. Préface de Jacques DALARUN, Bruxelles, Société des Bollandistes (« Subsidia hagiographica », 90), 2010, 25 cm, IX-255 p., $65 €$, ISBN 978-2-87365-024-7.

1 Dans le maquis des témoignages, des Vies et des miracles, qui constituèrent, année après année, le volumineux dossier des légendes franciscaines, il demeurait encore bien des sentiers mal explorés, parmi lesquels une vexata quaestio concernant la Legenda $S$. Clarae virginis (répertoriée sous le $\mathrm{n}^{\circ} 1815$ dans la Bibliotheca hagiographica latina). Claire, pourtant, n'avait pas eu à attendre trop longtemps son hagiographe: deux mois seulement après sa mort, survenue le 11 août 1253, le pape Innocent IV ouvrait le procès de sa canonisation, prononcée par Alexandre IV en 1255. La Legenda S. Clarae fut rédigée dans les années qui suivirent (mais avant la translation de 1260), à la demande du pape lui-même, par un hagiographe dont les manuscrits conservés omettent de transmettre le nom. Ce texte était néanmoins cité sous le nom de Thomas de Celano, l'hagiographe de François d'Assise, par Battista Alfani (†1523), une clarisse du monastère Monteluce de Pérouse. Celle-ci était particulièrement versée dans la question clarienne, puisqu'elle traduisit en volgare les Actes latins du procès de 
canonisation de la sainte. Jusqu'à aujourd'hui, cependant, son témoignage tardif n'avait pas reçu l'approbation totale et définitive de la critique moderne: les spécialistes hésitaient en effet entre cette attribution à Thomas de Celano (entérinée dans la Bibliotheca hagiographica latina) et d'autres hypothèses : un manuscrit perdu du XIV ${ }^{\mathrm{e}}-\mathrm{XV}^{\mathrm{e}}$ s., utilisé par l'édition des Acta Sanctorum, donnait en effet le nom de Bonaventure, accepté par certains; aussi, d'autres chercheurs, comme le dernier éditeur de la Legenda S.Clarae, G. Boccali, préféraient-ils évoquer, plus prudemment, un lettré anonyme. Même s'il existait de sérieuses présomptions en faveur de Thomas de Celano, la démonstration de sa paternité n'avait jamais été menée entièrement, et c'est à cette enquête d'attribution qu'est consacrée l'étude de M. Guida, fruit d'une recherche doctorale soutenue en 2007 auprès de la Pontificia Università Gregoriana de Rome.

Pour gravir le versant philologique de cette mission, il fallait d'abord s'enquérir des sources de la Legenda S. Clarae, formée, comme la plupart des textes hagiographiques médiévaux, d'une marqueterie textuelle. On ne saurait en effet disserter sur le style et la langue d'un auteur en traitant de manière indifférenciée ses phrases originales et ses emprunts: la comparaison minutieuse de la légende clarienne et de ses sources permettrait donc d'isoler les apports propres de l'hagiographe. Dans le cas présent, la situation était d'autant plus complexe que les sources de la Legenda S. Clarae ne nous sont parvenues que de manière imparfaite. Nous possédons bien, il est vrai, la lettre d'Innocent IV ouvrant le procès de Claire (la lettre Gloriosus Deus charge l'évêque Barthélémy de Spolète de rassembler tous les témoignages relatifs à la vie et aux miracles de Claire), ainsi que la bulle de canonisation d'Alexandre IV (lettre Clara claris praeclara, inscrivant Claire au calendrier des saints); mais, pour les Actes du procès (la documentation réunie par les enquêteurs et transmise pour examen à la Curie romaine), nous n'avons plus que la traduction vernaculaire de Battista Alfani; les quelques fragments latins conservés dans le manuscrit München, BSB, Clm. 23846, permettent toutefois d'en établir la fiabilité. Pour faciliter la comparaison des textes, qui occupe le cœur de son ouvrage, M. Guida a mis au point une confrontation synoptique de la Legenda S. Clarae et de ses sources principales: différents codes de couleur mettent à nu la marqueterie des sources, tandis que les grasses distinguent les emprunts ad litteram des simples remplois de contenu. Il apparaît ainsi que l'hagiographe utilisa massivement les Actes du procès (les correspondances entre son texte et la traduction de Battista Alfani apparaissent en bleu dans les tableaux de M. Guida), mais n'en négligea pas pour autant la bulle de canonisation (emprunts signalés en rouge), les écrits de Claire elle-même (en vert), ainsi que plusieurs textes du dossier franciscain (emprunts récurrents aux Legendae de Thomas de Celano, notés en violet, emprunts à la Vita S. Francisci de Julien de Spire, notés en jaune). Les passages laissés en noir dans cette confrontation synoptique révèlent le proprium de l'hagiographe, qui semble d'ailleurs avoir bénéficié, pour compléter son travail, des témoignages oraux des compagnons de François - à commencer par celui de frère Léon - et des sœurs de Saint-Damien.

Grâce à cette Quellenforschung novatrice et systématique, M. Guida a pu pousser beaucoup plus loin que ses prédécesseurs l'analyse de la Legenda S. Clarae et la critique de son attribution. En faveur de Thomas de Celano, il a ainsi réuni tout un faisceau d'indices externes et internes, à ajouter au témoignage crédible de Battista Alfani. Thomas de Celano, en effet, avait été, en quelque sorte, l'hagiographe officiel de François : il était donc normal que le pape lui confiât également la rédaction d'une Vie 
de Claire, sachant que les deux dossiers étaient déjà, à l'époque, intrinsèquement liés (la Legenda S. Clarae apparaît ainsi dans le plus ancien et plus important témoin du dossier franciscain, le ms. Assisi, Sacro Convento, 338). Quant au contenu, il révèle un frère mineur, manifestement très proche des premiers fidèles de François (Claire, Léon, Ange, Élie, et Thomas de Celano lui-même); ses thèmes de prédilection, perceptibles dans des ajouts et des omissions volontaires, rejoignent ceux de l'hagiographe franciscain. Les travaux qu'avait menés Hoonhout, en 1947, sur le lexique de Thomas de Celano, allaient d'ailleurs déjà dans le sens d'une attribution à ce dernier de la Legenda S. Clarae; avec les analyses de M. Guida sur le cursus du prologue, et sur le style en général de l'hagiographe, toujours soucieux de conserver une sobre élégance, cette paternité se trouve corroborée de manière convaincante.

4 Une telle enquête, dans l'épais dossier des sources en présence, aurait pu se perdre dans la confusion et l'obscurité, mais l'ouvrage de M. Guida prouve, s'il en était besoin, que l'on peut se pencher sur les questions les plus rebattues avec rigueur et pragmatisme. Il faut saluer ici la clarté du propos, ainsi que l'évidence colorée des tableaux synoptiques qui le jalonnent. C'est une démonstration patiente, minutieuse, et qui fait honneur à son auteur et à la vigueur actuelle des études sur l'hagiographie franciscaine.

\section{AUTEURS}

\section{CÉCILE LANÉRY}

Institut de Recherche et d'Histoire des Textes, Paris. 